\title{
AKTIVITAS ANTIOKSIDAN EKSTRAK BUNGA WIJAYA KUSUMA \\ (Epiphyllum oxypetalum)
}

\section{ANTI-OXIDANT ACTIVITY OF LADY FLOWERS (Epiphyllum oxypetalum) EXTRACT}

\author{
NI PUTU RAHAYU ARTINI*•, I WAYAN TANJUNG ARYASA*
}

\author{
*Program Studi Teknologi Laboratorium Medik, Institut Ilmu Kesehatan Medika Persada Bali
}

\begin{abstract}
Abstrak: Telah dilakukan isolasi dan uji screening fitokimia fraksi antioksidan dari bunga wijaya kusuma (Epiphyllum oxypetalum). Ekstraksi metabolitnya dilakukan secara maserasi menggunakan metanol sehingga dihasilkan 45,2579 gram ekstrak kental metanol. Ekstrak kental metanol ini memiliki persen peredaman DPPH sebesar $66,42 \%$ pada menit ke-5 dan $70 \%$ pada menit ke-60. Partisi dilakukan menggunakan petroleum eter, etilasetat, dan lapisan air hingga diperoleh ekstrak petroleum eter yang memiliki persen peredaman paling besar, yaitu $60 \%$ pada menit ke-5 dan $155,1 \%$ pada menit ke-60. Senyawa yang terkandung dalam ekstrak petroleum eter bunga wijaya kusuma (Epiphyllum oxypetalum) adalah alkaloid, triterpenoid, dan saponin. Senyawa metabolit tersebut dapat menghaemolisis darah, sehingga bersifat toksik dan memiliki bioaktivitas sebagai antifeedant.
\end{abstract}

Kata kunci: alkaloid, bunga wijaya kusuma, screening fitokimia, triterpenoid, saponin.

Abstract: Isolation and phytochemical screening of anti-oxidant active isolate from the flower's lady of the night (Epiphyllum oxypetalum) was carried out in this study. Methanol was applied to maceration a 45.2579 gram sample. This crude extract showed $66.42 \%$ of inhibition ability to reduce oxidation DPPH (diphenylpicrylhydrazine) at the fifth minute and $70 \%$ at the sixtieth minute inhibition time. Petroleum ether, ethyl acetate, and water were applied to separate it. Petroleum ether extract has the highest anti-oxidant reduction percentage, which was $60 \%$ of inhibition ability to reduce oxidation in the fifth minute and $155.1 \%$ at the sixtieth minute inhibition time. The results of phytochemical screening indicated that Epiphyllum oxypetalum petroleum ether extract contains several secondary metabolite compounds including alkaloids, triterpenoids, and saponins. The compound can blood hemolysis, so have the toxicity, and bioactivity as anti feedant.

Key word: partition, phytochemical screening, saponin, the flowers lady of night, triterpenoid.

\section{PENDAHULUAN}

Dalam kehidupan sehari-hari, kita tidak dapat terbebas dari senyawa radikal bebas. Asap rokok, makanan yang digoreng, dibakar, paparan sinar matahari berlebih, asap kendaraan bermotor, obat-obatan sintetik, racun dan polusi udara merupakan beberapa sumber pembentuk senyawa radikal bebas di dalam tubuh. Jumlah radikal bebas yang terus meningkat dalam tubuh dapat memicu munculnya penyakit degeneratif seperti kanker, diabetes, peradangan dan kardiovaskuler (Denny et $a l, 2015)$.

Untuk melindungi diri dari radikal bebas, tubuh menghasilkan senyawa anti radikal bebas atau disebut juga antioksidan. Antioksidan merupakan senyawa yang dapat memperlambat atau mencegah terjadinya kerusakan yang diakibatkan oleh radikal bebas dengan jalan meredam aktivitas radikal bebas atau memutus rantai reaksi oksidasi yang disebabkan oleh radikal bebas. Penggunaan antioksidan sintetik dewasa ini mulai mendapat perhatian serius karena ada yang bersifat merugikan dan karsinogenik. Oleh karena itu saat ini tengah digalakkan pengembangan antioksidan yang berasal dari alam, yang relatif lebih mudah didapat dan aman dikonsumsi manusia (Jung et al, 2006)

Berbagai bukti ilmiah menunjukkan bahwa resiko penyakit kronis akibat senyawa radikal bebas dapat dikurangi dengan memanfaatkan peran senyawa antioksidan seperti vitamin $\mathrm{C}, \mathrm{E}, \mathrm{A}$, karoten, asam-asam fenol, polifenol dan flavonoid (Prakash, 2001; Okawa et al., 2001). Tumbuhtumbuhan mengandung senyawa fitokimia yang mampu berperan sebagai antioksidan. Antioksidan

\footnotetext{
• Author correspondence. e-mail: artinirahayu967@gmail.com
} 
yang terdapat dalam tumbuh-tumbuhan dapat digunakan untuk melawan stres oksidatif, untuk melindungi sel dari kerusakan oksidatif dan mencegah penyakit kronis seperti kanker, penyakit kardiovaskular dan diabetes (Benjapak et al., 2008).

Antioksidan alami mampu melindungi tubuh terhadap kerusakan yang disebabkan spesies oksigen reaktif, mampu menghambat terjadinya penyakit degeneratif serta mampu menghambat peroksidase lipid pada makanan. Meningkatnya minat untuk mendapatkan antioksidan alami terjadi beberapa tahun terakhir ini. Bunga Wijaya Kusuma (Epiphyllum oxypetalum) segar atau batang yang masih segar digunakan untuk mengatasi radang, luka dan bisul, dan pemakaian dalam untuk mengatasi batuk, antiradang, dll. Belum banyak yang mengetahui khasiat dari tanmanan ini. Bunga wijaya kusuma dikenal sebagai ratu malam, dikarenakan aktivitas mekarnya bunga ini hanya pada malam hari, sedangkan esok paginya disaat matahari telah terbit bungan ini langsung layu.

Beberapa orang percaya bahwa mengkonsumsi seduhan bunga wijaya kusuma, yaitu bunganya dikeringkan kemudian dikonsumsi dengan direbus kemudian airnya diminum dapat menghilangkan rasa sakit pada kepala, meredakan peradangan bagi yang memiliki serangan batuk atau asma. Bagian batangnya juga dapat digunakan sebagai obat luka dan menetralkan pembekuan darah, serta mengobati abses. Namun, belum adanya informasi tentang manfaat dari tanaman bunga wijaya kusuma.

Berdasarkan uji skrining fitokimia yang telah dilakukan, bunga wijaya kusuma mengandung beberapa metabolit sekunder seperti saponin, flavonoid dan steroid. Namun secara ilmiah belum ada penelitian secara fitofarmakologi mengenai kandungan kimia pada tanaman wijaya kusuma. Berdasarkan literatur sejauh ini belum adanya uji bioaktivitas bunga wijaya kusuma (Epiphyllum oxypetalum), salah satunya sebagai antioksidan, oleh karena itu perlu adanya isolasi dan identifikasi untuk penentuan aktivitas antioksidan serta senyawa aktif pada bunga wijaya kusuma.

\section{METODE PENELITIAN}

Alat Penelitian. Peralatan yang digunakan pada penelitian ini adalah pisau, blender, ayakan, neraca analitik (Merk Matrix type Esj 210-4B) labu ukur, gelas piala, gelas ukur, desikator, pipit volume, batang pengaduk, ball filler, kertas saring, vakum putar penguap (rotary vacum evaporator), corong pisah, dan seperangkat alat spektrofotometer UVVis (Merk Amtast AMV11).

Sampel Penelitian. Sampel yang digunakan pada penelitian ini adalah bunga wijaya kusuma (Epiphyllum oxypetalum) yang diperoleh dari daerah sekitar Denpasar dan Badung. Sampel dikeringkan dengan cara diangin-anginkan dan tidak kontak langsung dengan sinar matahari. Proses pengeringan dilakukan hingga diperoleh bentuk simplisia dengan kadar air tidak lebih dari $10 \%$.

Bahan kimia yang digunakan pada penelitian ini yaitu metanol (p.a), akuades, kristal 2,2-difenil-1pikrilhidrazil, asam klorida 37\%, pereaksi natrium hidroksida $10 \%$, pereaksi Wilstatter, pereaksi Bate-Smith dan Metacalf, pereaksi Wagner, pereaksi Lieberman-Burchard, pereaksi asam sulfat $10 \%$, dan pereaksi besi (III) klorida $1 \%$.

\section{Metode Penelitian.}

Penyiapan Bahan. Bunga Wijaya Kusuma (Epiphyllum oxypetalum) yang dibersihan, dikeringkan, dan dipotong kecil-kecil di blender kemudian diayak sehingga menjadi serbuk berwarna coklat dan ditimbang dengan neraca analitik.

Ekstraksi bunga wijaya kusuma. Sebanyak 250 gram serbuk wijaya kusuma (Epiphyllum oxypetalum) diekstraksi dengan cara maserasi menggunakan metanol dan setiap maserasi digunakan $500 \mathrm{~mL}$ metanol, kemudian disaring. Ekstrak metanol dipisahkan dari pelarutnya dengan menggunakan rotary vacum evaporator sehingga diperoleh ekstrak kental metanol. Ekstrak ini kemudian dimasukkan dalam desikator sehingga diperoleh ekstrak kering. Ampas yang diperoleh dimaserasi kembali dengan pelarut metanol sampai diperoleh filtrat bening yang diperkirakan senyawa aktif dalam serbuk wijaya kusuma telah habis. Lalu dilakukan pengujian screening fitokimia pada ekstrak methanol wijaya kusuma (Epiphyllum oxypetalum).

\section{Uji aktivitas antioksidan secara spektroskopi}

Pengujian antioksidan dilakukan terhadap ekstrak kental yang diperoleh dengan beberapa tahapan sebagai berikut:

\section{Pembuatan larutan sampel}

Sebanyak 0,08 gram ekstrak diencerkan dengan etanol pada labu ukur $10 \mathrm{~mL}$ sehingga kadarnya menjadi 8000 ppm. 
2. Pembuatan larutan DPPH

Kristal DPPH ditimbang seberat 0,0004 gram dengan menggunakan neraca analitik lalu dilarutkan dalam etanol dengan menggunakan labu ukur $10 \mathrm{ml}$ sehingga kadarnya 0,004\% $(\mathrm{b} / \mathrm{v})$.

3. Pengujian Aktivitas Antiradikal Bebas

\section{a. Pengukuran Absorbansi DPPH}

Absorbansi DPPH diukur pada panjang gelombang $(\lambda) \quad 400-700 \mathrm{~nm}$ (sinar tampak). Larutan blanko yang digunakan adalah etanol. Pencatatan dilakukan terhadap absorbansi pada panjang gelombang $497 \mathrm{~nm}, 517 \mathrm{~nm}$, dan $537 \mathrm{~nm}$.

b. Pengukuran Absorbansi Sampel

Sejumlah $1 \mathrm{ml}$ sampel dimasukan ke dalam kuvet lalu ditambahkan ke dalamnya $2 \mathrm{ml}$ larutan DPPH 0,004\%. Campuran tersebut kemudian diaduk rata dengan menggunakan pipet. Pada menit ke-5 dan ke-60 setelah reaksi berlangsung, dilakukan pencatatan absorbansi pada panjang gelombang $497 \mathrm{~nm}, 517 \mathrm{~nm}$, dan $537 \mathrm{~nm}$.

Partisi. Ekstrak kental metanol dilarutkan dalam air-metanol (7:3), kemudian dipartisi dengan petroleum eter $(5 \times 50 \mathrm{~mL})$. Ekstrak n-heksan dikumpulkan dan dan residunya (ekstrak air) dipartisi kembali dengan etil asetat $(5 \times 50 \mathrm{~mL})$. Ekstrak etilasetat dikumpulkan dan lapisan air dikumpulkan lalu ketiga ekstrak diuapkan dengan vacum evaporator sehingga diperoleh ekstrak kental petroleum eter, etilasetat, dan air. Ketiga ekstrak yang diperoleh kemuadian diuji aktivitas antioksidannya secara spektroskopi (Sudjadi, 1988).

\section{HASIL DAN PEMBAHASAN}

\section{Ekstraksi}

Bunga wijaya kusuma (Epiphyllum oxypetalum) yang dipergunakan pada penelitian ini berasal dari daerah Denpasar dan Badung serta tumbuh di daerah pekarangan rumah untuk meminimalisir adanya gas pencemar. Langkah awal dalam proses penyiapan sampel adalah dilakukan uji determinasi di Balai Konversi Tumbuhan Kebun Raya Eka Karya Bedugul, Bali menunjukkan bahwa bunga wijaya kusuma yang digunakan pada penelitian ini termasuk spesies Epiphyllum oxypetalum.

Sampel terlebih dahulu dibersihan, dikeringkan tanpa terkena sinar matahari secara langsung, dan dipotong kecil-kecil lalu dibuat menjadi serbuk kemudian diayak sehingga menjadi serbuk berwarna hijau kecoklatan dan ditimbang dengan neraca analitik. Sebanyak 500 gram serbuk bunga wijaya kusuma (Epiphyllum oxypetalum) diekstraksi dengan cara maserasi menggunakan metanol teknis selama \pm 24 jam, kemudian disaring sehingga diperoleh filtrat dan residu, sehingga didapat filtrat seluruhnya sebanyak 10 liter dari 13 liter metanol. Filtrat yang diperoleh dikumpulkan dan diuapkan dengan menggunakan rotary vacum evaporator. Hasil uapan tersebut diperoleh ekstrak kental metanol yang berwarna hijau kehitaman sebanyak 45,2579 gram.

\section{Uji Aktivitas Antioksidan Ekstrak Kental Metanol}

Ekstrak kental metanol bunga wijaya kusuma (Epiphyllum oxypetalum) diuji aktivitas antioksidannya secara spektroskopi dengan menggunakan senyawa DPPH (difenilpicrylhydrazine) yang memiliki kadar 0,004\% (b/v) dengan konsentrasi sampel 8000 ppm. Larutan DPPH bersifat sebagai radikal kuat yang stabil dan berwarna ungu. Suatu sampel akan bersifat sebagai antioksidan bila sampel tersebut dapat meredam dan menyerap warna ungu menjadi berwarna cerah seperti hijau atau kuning.

Berdasarkan uji aktivitas antioksidan pada Tabel 1, menunjukkan bahwa ekstrak Epiphyllum oxypetalum memiliki potensi yang sebagai antioksidan. Hal ini dapat dilihat dari persentase peredamannya yang tinggi, yaitu sebesar $66,42 \%$ pada menit ke-5 dan 70,00 \% pada menit ke-60. Suatu bahan dikatakan aktif bersifat antioksidan jika memiliki persentase peredaman lebih besar atau sama dengan $50 \%$ (Djatmiko, 1998).

Tabel 1. Hasil uji aktivitas antioksidan ekstrak metanol Epiphyllum oxypetalum

\begin{tabular}{|c|c|c|c|c|c|c|c|}
\hline \multirow[b]{2}{*}{ Sampel } & \multirow{2}{*}{$\begin{array}{l}\text { Waktu } \\
\text { (menit) }\end{array}$} & \multirow{2}{*}{ Uji } & \multicolumn{3}{|c|}{ Absorbansi } & \multirow{2}{*}{$\underset{\mathrm{nm}}{\text { A hitung } 517}$} & \multirow{2}{*}{$\begin{array}{c}\% \\
\text { peredaman }\end{array}$} \\
\hline & & & $497 \mathrm{~nm}$ & $517 \mathrm{~nm}$ & $537 \mathrm{~nm}$ & & \\
\hline \multirow{4}{*}{$\begin{array}{c}\text { Ekstrak } \\
\text { kental } \\
\text { metanol }\end{array}$} & \multirow[b]{2}{*}{5} & DPPH & 0,758 & 0,799 & 0,703 & $0,0685 \pm 0,015$ & \multirow[b]{2}{*}{$66,42 \%$} \\
\hline & & Sampel & 0,715 & 0,698 & 0,635 & $0,0230 \pm 0,018$ & \\
\hline & \multirow{2}{*}{60} & DPPH & 0,749 & 0,781 & 0,693 & $0,0600 \pm 0,014$ & \multirow{2}{*}{$70,00 \%$} \\
\hline & & Sampel & 0,693 & 0,676 & 0,623 & $0,0180 \pm 0,011$ & \\
\hline
\end{tabular}


Ekstrak Epiphyllum oxypetalum yang diuji merupakan ekstrak kasar yang masih mengandung semua senyawa terlarut yang bersifat polar, semipolar, dan nonpolar sehingga sifat antioksidan yang dihasilkan melalui peredaman warna belum spesifik berdasarkan sifat kepolaran senyawa yang bertindak sebagai antioksidan. Lalu dilanjutkan dengan pemisahan senyawa berdasarkan tingkat kepolarannya melalui partisi sampel.

\section{Partisi Sampel}

Ekstrak kental metanol Epiphyllum oxypetalum yang digunakan untuk partisi sebanyak 40 gram kemudian dilarutkan dalam $100 \mathrm{~mL}$ air dan metanol (7:3), selanjutnya dilakukan partisi untuk memisahkan senyawa-senyawa kimia dalam ekstrak kasar berdasarkan kepolarannya. Hasil partisi diperoleh ekstrak kental petroleum eter sebanyak 6,8730 gram yang berwarna merah kecoklatan, ekstrak kental etilasetat sebanyak 31,0675 gram yang berwarna merah kecoklatan, dan ekstrak air sebanyak 2,0595 gram yang berwarna coklat.

Ekstrak petroleum eter, etilasetat dan air kemudian diuji aktivitas antioksidannya. Hasil uji aktivitas antioksidan beberapa fraksi hasil partisi dapat dilihat pada Tabel 2. Hasil uji aktivitas antioksidan pada Tabel 1, menunjukkan fraksi petroleum eter, etilasetat, dan air bersifat aktif sebagai antioksidan. Ekstrak petroleum eter memiliki persentase peredaman paling tinggi pada menit ke-5 sebesar $60 \%$ dan menit ke-60 sebesar $155,1 \%$, diikuti dengan ekstrak air memiliki persentase peredaman $27 \%$ pada menit ke-5 dan $74,3 \%$ pada menit ke-60, dan aktivitas antioksidan paling rendah dimiliki oleh ekstrak etilasetat, yaitu $45 \%$ pada menit ke-5 dan 57\% pada menit ke-60.

Tabel 2. Hasil partisi ekstrak Epiphyllum oxypetalum dengan beberapa pelarut

\begin{tabular}{ccc}
\hline Ekstrak & Berat (gram) & Warna \\
\hline Petroleum eter & 6,8730 & Merah kecoklatan \\
\hline Etilasetat & 31,0675 & Merah kecoklatan \\
\hline Air & 2,0595 & Coklat
\end{tabular}

\section{Uji Fitokimia Ekstrak Petroleum Eter}

Ekstrak petroleum eter, etilasetat dan air kemudian diuji aktivitas antioksidannya. Hasil uji aktivitas antioksidan beberapa fraksi hasil partisi dapat dilihat pada Tabel 3. Hasil uji aktivitas antioksidan pada Tabel 5.3, menunjukkan fraksi petroleum eter, etilasetat, dan air bersifat aktif sebagai antioksidan. Ekstrak petroleum eter memiliki persentase peredaman paling tinggi pada menit ke-5 sebesar $60 \%$ dan menit ke-60 sebesar $155,1 \%$. Ekstrak petroleum eter kemudian diuji fitokimia.

Tabel 3. Hasil uji aktivitas antioksidan pada ekstrak kental hasil partisi

\begin{tabular}{|c|c|c|c|c|c|c|c|}
\hline \multirow{2}{*}{ Fraksi } & \multirow{2}{*}{$\begin{array}{l}\text { Waktu } \\
\text { (menit) }\end{array}$} & \multirow{2}{*}{ Uji } & \multicolumn{3}{|c|}{ Absorbansi } & \multirow{2}{*}{$\begin{array}{c}\text { A hitung } 517 \\
\text { nm }\end{array}$} & \multirow{2}{*}{$\begin{array}{c}\% \\
\text { peredaman }\end{array}$} \\
\hline & & & $497 \mathrm{~nm}$ & $517 \mathrm{~nm}$ & $537 \mathrm{~nm}$ & & \\
\hline \multirow{4}{*}{$\begin{array}{l}\text { Fraksi } \\
\text { PE }\end{array}$} & \multirow{2}{*}{5} & DPPH & 0,614 & 0,589 & 0,464 & $0,0500 \pm 0,012$ & \multirow{2}{*}{$60 \%$} \\
\hline & & Sampel & 0,235 & 0,237 & 0,169 & $0,0350 \pm 0,015$ & \\
\hline & \multirow{2}{*}{60} & DPPH & 0,422 & 0,420 & 0,369 & $0,0245 \pm 0,021$ & \multirow{2}{*}{$155,1 \%$} \\
\hline & & Sampel & 0,201 & 0,183 & 0,154 & $0,0055 \pm 0,018$ & \\
\hline \multirow{4}{*}{$\begin{array}{c}\text { Fraksi } \\
\text { etilasetat }\end{array}$} & \multirow{2}{*}{5} & DPPH & 0,612 & 0,624 & 0,576 & $0,0300 \pm 0,020$ & \multirow{2}{*}{$45 \%$} \\
\hline & & Sampel & 0,607 & 0,564 & 0,488 & $0,0165 \pm 0,021$ & \\
\hline & \multirow{2}{*}{60} & DPPH & 0,673 & 0,659 & 0,587 & $0,0290 \pm 0,015$ & \multirow{2}{*}{$57 \%$} \\
\hline & & Sampel & 0,487 & 0,457 & 0,402 & $0,0125 \pm 0,021$ & \\
\hline \multirow{4}{*}{$\begin{array}{l}\text { Fraksi } \\
\text { Air }\end{array}$} & \multirow{2}{*}{5} & DPPH & 0,625 & 0,689 & 0,603 & $0,0750 \pm 0,025$ & \multirow{2}{*}{$27 \%$} \\
\hline & & Sampel & 0,422 & 0,398 & 0,264 & $0,0550 \pm 0,021$ & \\
\hline & \multirow{2}{*}{60} & DPPH & 0,615 & 0,638 & 0,591 & $0,0350 \pm 0,012$ & \multirow{2}{*}{$74,3 \%$} \\
\hline & & Sampel & 0,400 & 0,370 & 0,254 & $0,0180 \pm 0,018$ & \\
\hline
\end{tabular}

Berdasarkan pengujian fitokimia (Disajikan pada Tabel 4) golongan alkaloid memberikan hasil positif dengan menggunakan pereaksi Meyer dan Pereaksi Wagner. Hasil dengan menggunakan pereaksi Meyer adalah munculnya endapan putih dengan larutan berwarna kuning pada plat tetes, begitu pula dengan menggunakan pereaksi Wagner menghasilkan endapan coklat pada plat tetes, hasil ini menunjukkan hasil positif mengandung metabolit sekunder golongan alkaloid. Dilakukan dengan menggunakan dua pereaksi bertujuan untuk 
menghindari adanya hasil positif palsu (Novi, 2008).

Untuk pengujian golongan metabolit sekunder triterpenoid dan steroid menggunakan pereaksi yang sama, yaitu pereaksi LiebermanBurchard dan $\mathrm{H}_{2} \mathrm{SO}_{4} \quad 10 \%$ yang hasilnya menunjukkan perubahan warna dari kuning menjadi coklat, ini menunjukkan ekstrak petroleum eter positif mengandung triterpenoid. Bila positif mengandung steroid, sampel akan menunjukkan perubahan warna menjadi hijau sampai biru. Salah satu golongan terpenoid adalah karatenoid, yaitu pigmen yang berwarna kuning sampai merah yang terdapat pada semua tumbuhan tingkat tinggi. Namun, adapula pigmenyang tidak berwarna yang dikenal sebagai xantofil, yaitu turunan terpenoid yang teroksigenasi dari hidrokarbon karoten. Ekstrak Epiphyllum oxypetalum termasuk golongan xantofil yang tidak memiliki pigmen berwarna kuning sampai merah.

Tabel 4. Hasil uji fitokimia ekstrak petroleum eter

\begin{tabular}{|c|c|c|c|c|}
\hline No. & $\begin{array}{l}\text { Uji fitokimia } \\
\text { senyawa }\end{array}$ & Pereaksi & Perubahan & Simpulan \\
\hline \multirow{2}{*}{1.} & \multirow{2}{*}{ Alkaloid } & Meyer & Kuning - end. Putih & + \\
\hline & & Wagner & Kuning - end.coklat & \\
\hline \multirow{4}{*}{2.} & \multirow{4}{*}{ Flavonoid } & Wilstatter & Kuning - coklat & - \\
\hline & & $\mathrm{NaOH} 10 \%$ & Kuning - kuning tua & - \\
\hline & & $\mathrm{H}_{2} \mathrm{SO}_{4}$ pekat & Kuning - kuning keruh & - \\
\hline & & Bate Smith-Metacalf & Kuning - coklat & - \\
\hline \multirow{2}{*}{3.} & \multirow{2}{*}{ Triterpenoid } & Lieberman-Burchard & Kuning - coklat & + \\
\hline & & $\mathrm{H}_{2} \mathrm{SO}_{4} 10 \%$ & Kuning - coklat & + \\
\hline 4. & Saponin & Air panas $+\mathrm{HCl}$ pekat & Busa stabil & + \\
\hline 5. & Fenolat (tannin) & Air panas $+\mathrm{FeCl}_{3} 1 \%$ & Kuning - hijau muda & - \\
\hline \multirow[b]{2}{*}{6.} & \multirow{2}{*}{ Steroid } & Lieberman-Burchard & Kuning - coklat & - \\
\hline & & $\mathrm{H}_{2} \mathrm{SO}_{4} 10 \%$ & Kuning - coklat & - \\
\hline
\end{tabular}

Keterangan:

$(+)=$ Mengandung senyawa yang dimaksud

$(-)=$ Tidak mengandung senyawa yang dimaksud

Senyawa golongan terpenoid selain ditemukan dalam bentuk karoten atau pigmen berwarna, juga ditemukan dalam bentuk monoterpen. Monoterpen adalah golongan terpenoid berupa isopren yang memiliki struktur siklik terbuka dan di alam ditemukan sebagai komponen senyawa minyak atsiri. Komponen minyak atsiri juga terdapat pada bunga wijaya kusuma, sehingga berdasarkan uji metabolit sekunder positif mengandung terpenoid golongan triterpenoid (Novi, 2008).

Fraksi petroleum eter juga positif mengandung saponin. Hasil pengujian metabolit sekunder ditandai dengan terbentuknya busa setelah penambahan air panas, dan busa akan tetap stabil bila ditambahkan $\mathrm{HCl}$ pekat (Harborne, J.B., 1987). Saponin adalah golongan metabolit sekunder yang dapat menghaemolisis darah, sehingga bersifat toksik dan memiliki bioaktivitas sebagai antifeedant (Djatmiko, S., 1998).

Golongan metabolit sekunder yang ditemukan pada fraksi petroleum eter Epiphyllum oxypetalum seluruhnya adalah metabolit yang memiliki kelarutan pada fraksi nonpolar, yaitu terpenoid, alkaloid, dan saponin yang memiliki aktivitas sebagai insektisida, antifeedant, antimikroba, dan bersifat toksik (Novi, 2008) Sedangkan, fraksi petroleum eter Epiphyllum oxypetalum tidak menunjukkan hasil positif mengandung flavonid dan fenolat dikarenakan semua senyawa yang polar terlarut pada fraksi air Epiphyllum oxypetalum.

\section{SIMPULAN}

Berdasarkan hasil penelitian dan pembahasan, maka dapat disimpulkan sebagai berikut :

1 Persentase aktivitas antioksidan pada ekstrak kasar wijaya kusuma (Epiphyllum oxypetalum) pada menit ke-5 adalah $66,42 \%$ dan $70,00 \%$ pada menit ke-60 dan fraksi aktif bunga wijaya kusuma (Epiphyllum oxypetalum) adalah fraksi petroleum eter pada menit ke-5 adalah $60 \%$ dan $155,10 \%$ pada menit ke- 60 .

2 Senyawa yang terkandung dalam ekstrak petroleum eter bunga wijaya kusuma (Epiphyllum oxypetalum) berdasarkan uji screening fitokimia adalah alkaloid, triterpenoid, dan saponin. 


\section{DAFTAR PUSTAKA}

Benjapak, N, Prasan Swasitang, Sayan Tanpanich, 2008, Determination of Antioxidant Capacity and Nurtritive Values of PakWanban (Sauropus androgynus L.Merr), Kku Sci.J.36(4) 279-289

Denny, et al, 2015, Uji Aktivitas Antioksidan terhadap DPPH dan ABTS dari fraksifraksi Daun Kelor (Moringa Oleifera), Prosiding Simposium Nasional Inovasi dan Pembelajaran Sains 2015

Djatmiko, S., 1998, Seminar Nasional Tumbuhan Obat XII, Fakultas Farmasi Unair, Surabaya.
Harborne, J.B., 1987, Metode Fitokimia : Penuntun Cara Modern Menganalisis Tumbuhan, Terjemahan Padmawinata, K., dan Soediro, I., Penerbit ITB, Bandung.

Jung, et al., 2005, AINS (antiinflamasi nonsteroid), Biopharmaca Research, Public Institude of New York, USA.

Novi, K, A., 2008, Buku Ajar Fitokimia, Airlangga University Press, Surabaya.

Sudjadi, 1988, Metode Pemisahan, Kanisius, Yogyakarta. 